\title{
Transgenic Humanized AHR Mouse Reveals Differences between Human and Mouse AHR Ligand Selectivity
}

\author{
Colin A. Flaveny and Gary H. Perdew \\ Center for Molecular Toxicology and Carcinogenesis and the Department of Veterinary and \\ Biomedical Sciences, the Pennsylvania State University, University Park, Pennsylvania
}

PharmSight on Flaveny CA, et al. Ligand selectivity and gene gegulation by the human aryl hydrocarbon receptor in transgenic mice. Mol Pharamacol 2009;75:1412-20.

\begin{abstract}
The Aryl-hydrocarbon receptor (AHR) is a ligand activated transcription factor involved in xenobiotic metabolism. Most of the toxic effects of halogenated and non-halogenated polycyclic aromatic hydrocarbons (HAHs and PAHs respectively) are mediated by the AHR. For the AHR, a number of intra and interspecies differences exist in terms of responsiveness to the prototypical AHR ligand 2,3,7,8-tetrachlorodibenzop-dioxin (TCDD). Interspecies differences in AHR ligand binding affinity has been shown to be linked to contrasting TCDD tolerance between species and among inbred strains of mice expressing different AHR alleles. Compared to the human AHR (hAHR), the mouse $A H R^{b}\left(m A H R^{b}\right)$ has a $\sim 10$ fold higher affinity for typical AHR ligands. Using a transgenic humanized mouse model that expresses hAHR protein specifically in the liver, we have discovered that for certain ligands, such as indirubin, the hAHR exhibits higher relative ligand binding affinity and responsiveness compared to the $\mathrm{mAHR}^{\mathrm{b}}$. These findings may potentially influence the ongoing search for endogenous hAHR ligands and expand our understanding of the unique physiological role of the hAHR.
\end{abstract}

Keywords: Aryl-hydrocarbon receptor; AHR ligands; Indirubin; TCDD; Polycyclic aromatic hydrocarbons

The Aryl hydrocarbon receptor (AHR) plays a significant role in the adaptive response to

Received 06/25/09; accepted 07/07/09

Correspondence: Gary H. Perdew, Ph.D., Center for Molecular Toxicology and Carcinogenesis and the Department of Veterinary and Biomedical Sciences, the Pennsylvania State University, University Park, PA16802, USA. Tel. 814-865-0400, Fax. 814-863-1696. email: ghp2@psu.edu xenobiotic exposure from dietary or environmental sources. The most studied pathway of AHR activation and subsequent stimulation of gene expression is typified by AHR induction of Phase I enzymes CYP1A1, CYP1B1, CYP1A2 and Phase II enzymes such as and glutathione S-transferase $Y a$ and aldehyde dehydrogenase $3 A I$. In addition to AHR-mediated xenobiotic metabolism, a number of studies in AHR knockout mice have established the physiological role of the AHR in liver and cardiac vascularization, reproductive organ development and immune cell function and differentiation (1-6).

The unliganded AHR exists as part of a stable multiprotein complex comprising of two molecules of heat shock protein 90 (HSP90), immunophilin-like AHR interacting protein (AIP also known as XAP2 and ARA9) and p23 $(7,8)$. Upon ligand binding the receptor dissociates from its cytoplasmic complex, translocates to the nucleus and heterodimerizes with the Aryl Hydrocarbon Receptor Nuclear Translocator (ARNT) (Figure 1). The resultant AHR/ARNT transcription factor heterodimer either binds to dioxin response elements; a six nucleotide consensus sequence (CGCGTG) and activates gene expression or represses the transcriptional activity of other receptors and transcription factors such as the estrogen receptor and NF-kB $(9,10)$.

The AHR mediates most of the toxic effects of exposure to the ubiquitous environmental contaminants HAHs and PAHs. Most notably, the AHR involved in the metabolism of benzo[a]pyrene, a component of cigarette smoke, to the ultimate carcinogen benzo[a]pyrene-4,5-epoxide and the resultant mutagenesis in mice (11). AHR expression and has also been shown to be important for TCDDinduced toxicity in mice (12). Clinical studies conducted on humans exposed to $\mathrm{HAHs}$ and $\mathrm{PAHs}$ as well as toxicity studies conducted in rodent model 


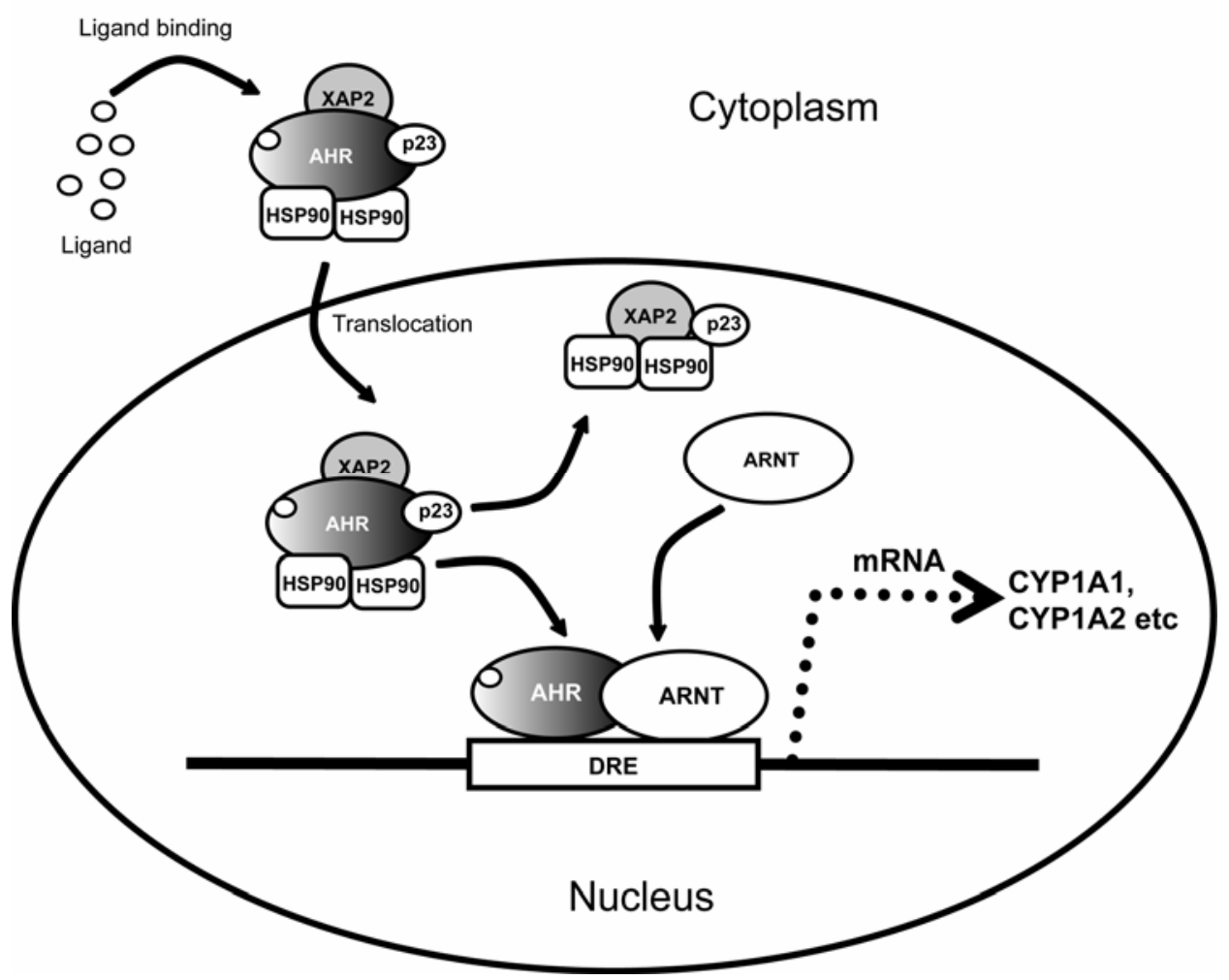

Figure 1. AHR ligand activation and gene induction. Ligand activation of the AHR promotes receptor nuclear translocation and eventual heterodimerization with ARNT. The ARNT/AHR heterodimer subsequently binds to dioxin responsive elements (DREs) leading to AHR-target gene activation.

systems have highlighted the contrasting interspecies effects of $\mathrm{PAH}$ and $\mathrm{HAH}$ exposure. Toxicity in mice and other rodents exposed to TCDD consists of a number symptoms including hepatomegaly, immune disruption, reproductive, developmental and neurological defects as well as cancer (13-15). Among various species with structurally divergent AHRs, there are substantial differences in dioxin responsiveness. Studies have shown there is at least a 1000-fold disparity in TCDD tolerance (as indicated by the differences in $\mathrm{LD}_{50}$ ) between the more sensitive guinea pigs and tolerant hamsters species (16). In comparison to the $\mathrm{mAHR}^{\mathrm{d}}$, the $\mathrm{mAHR}^{\mathrm{b}}$ has been shown to have a $\sim 10$ folder greater affinity for AHR ligands. The greater responsiveness to TCDD toxicity that C57BL6/J mice display compared to DBA mice is primarily linked to the higher relative ligand binding affinity of the $\mathrm{mAHR}^{\mathrm{b}}$ for dioxin relative to the $\mathrm{mAHR}^{\mathrm{d}}$ (Figure 2) (17). Similarly, the human AHR has 10fold lower affinity for TCDD compared with the $\mathrm{mAHR}^{\mathrm{b}}$. In humans, TCDD exposure has only been shown to cause chloracne and is tentatively linked to cognitive defects (18). In support of this discovery, past humanized mouse studies and various studies in a myriad of animal models, provide considerable evidence supporting the conclusion that impaired receptor-ligand binding correlates with TCDD resistance in vivo, which further suggests that humans may be resistant to TCDD-mediated toxicity (19). However, TCDD is still classified as a known human carcinogen by the EPA (20).

The C-terminal region of the AHR contains the transactivation domain and within this region there is considerable protein sequence degeneracy between species. There is only $58 \%$ similarity in the amino acid sequence identity in the C-terminal portions of the mAHR and hAHR (Figure 2). Recently, we showed that the amino acid sequence dissimilarity in the Q-rich transactivation subdomains of the hAHR and mAHR promotes differential recruitment of LXXLL co-activator binding motifs (21). As a consequence the hAHR and mAHR may recruit different subsets of co-activators which may suggest that the receptors function differently downstream of ligand binding. 


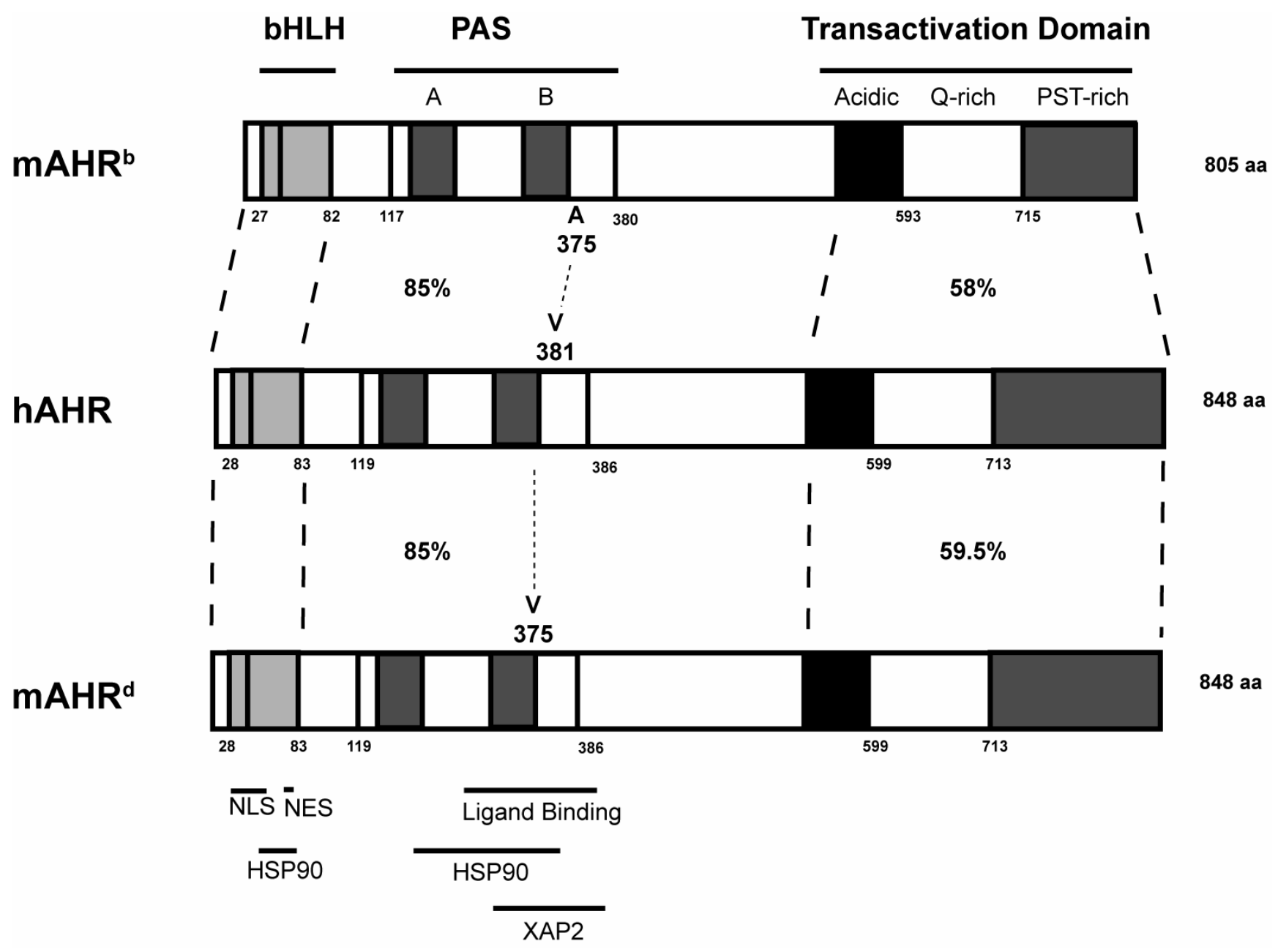

Figure 2. Comparison of human and mouse AHR protein structure. A number of amino acid sequence differences exist between the mouse alleles; $m A H R^{b}$ expressed in C57BL/6J mice and the mAHR ${ }^{d}$ allele of the DBA mouse strain and the hAHR. Due to an alanine residue in the ligand binding domain (A375 corresponding the V381 in the hAHR) the mAHR ${ }^{\mathrm{b}}$ has 10-fold higher relative affinity than both mAHR ${ }^{\mathrm{d}}$ and hAHR for typical AHR ligands like TCDD. The percentages given are relative to the human AHR.

Interestingly, the C-terminal domain of the hAHR has a high degree of homology to the AHR in the TCDD sensitive guinea pig AHR (22). Accordingly, the most potent CYP1A1 induction in response to TCDD was shown to be human lymphocytes in comparison to that of rat and mouse lymphocytes (23). For both the hAHR and all alleles of the mAHR, the $\mathrm{N}$-terminal domain houses the ligand binding domain. Between the $\mathrm{mAHR}^{\mathrm{b}}$ and hAHR there is $86 \%$ amino acid sequence similarity in the $\mathrm{N}$-terminal portions (Figure 2). The manner in which this structural divergence influences the biochemical functions of both receptors in vivo was the overall focus of our investigations. With this in mind we developed a transgenic mouse that expresses hAHR protein specifically in the liver under the control of the liver specific transthyretin promoter (strain name, B6 Cg-Ahrtm3.1Bra $\mathrm{Tg}(\mathrm{Alb}$-cre, Ttr-AHR)1 GHP) (24). Comparisons of mAHR and hAHR-driven gene expression profiles, using DNA microarrays, suggest that each receptor may regulate a unique subset of genes in response to TCDD (unpublished data).

Through comparison of competitive ligand binding and gene expression data in response to a variety of ligands we found that the hAHR has a higher relative affinity for indirubin. Previous mutational analysis of the hAHR ligand binding domain identified the valine residue (V381 in the hAHR and V375 in the mAHR ${ }^{\mathrm{d}}$ corresponding to A375 in the $\mathrm{mAHR}^{\mathrm{b}}$, see Figure 2) responsible for the reduced affinity the hAHR displays for TCDD relative to the $\mathrm{mAHR}^{\mathrm{b}}(25,26)$. Interestingly, for the hAHR mutation of V381 to the high ligand-binding 
affinity residue alanine failed to improve hAHR receptor binding and actually reduced indirubininduced hAHR transformation. Collectively these results suggest that the sequence degeneracy in the hAHR ligand binding domain may actually be a structural adaptation for interaction with indole metabolites. The hAHR ligand binding domain structure may thus be an evolutionary adaptation for response to endogenous ligands. These findings suggested that ligand pocket of the hAHR may bind a structurally distinct group of ligands compared to the $\mathrm{mAHR}^{\mathrm{b}}$. However, detailed understanding of the three-dimensional differences between the mAHR and hAHR ligand binding domain is a definite challenge without a detailed crystal structure of the mouse or human AHR currently available. Regardless, our investigations further supports previous work that suggested humans may be resistant to TCDD toxicity, and also suggests that there may be some previously unpredicted degree of functional and structural divergence between the mAHR and hAHR ligand binding domains.

Despite conferring a clearer understanding of the unique ligand binding properties of the hAHR, our findings have implications for future study of AHR biological function in humans. In particular, our investigations allude to the significant role indole metabolites may have in hAHR activation in humans due to the high affinity for these compounds displayed by the hAHR. Ever increasing lists of exogenous and endogenous compounds are being described as AHR ligands. Many of these compounds are assessed for their toxic or therapeutic properties using non-transgenic rodent model systems. Also a number of recent investigations have expanded the role of the hAHR in auto-immunity, normal immune cell function and differentiation and reproductive biology. As a consequence the AHR may become a future target for drugs aimed at attenuating endogenous AHR pathways. In light of these issues it becomes increasingly important to elucidate the functional disparities that may exist between the mAHR and hAHR, as data generated in studies conducted in in-bred rodent model systems may fail to accurately predict hAHR function in response to given ligands. Therefore, studies in humanized mouse model systems are important to the enhancement of our understanding of the physiological and toxicological roles of the AHR in humans.

\section{Acknowledgements}

This work was supported by NIH grant ES04869 and the Dow Chemical Company

\section{Conflicts of Interest}

No potential conflicts of interest to disclose.

\section{References}

1. Schmidt JV, Su GH-T, Reddy JK, Simon MC, Bradfield CA. Characterization of a murine Ahr null allele: Involvement of the Ah receptor in hepatic growth and development Proc Natl Acad Sci USA 1996;93:6731-6.

2. Abbott BD, Schmid JE, Pitt JA, Buckalew AR, Wood CR, Held GA, et al. Adverse reproductive outcomes in the transgenic Ah receptor-deficient mouse. Toxicol Appl Pharmacol 1999;155:62-70.

3. Robles R, Morita Y, Mann KK, Perez GI, Yang S, Matikainen $\mathrm{T}$, et al. The aryl hydrocarbon receptor, a basic helix-loop-helix transcription factor of the PAS gene family, is required for normal ovarian germ cell dynamics in the mouse. Endocrinology 2000;141:450-3.

4. Thackaberry EA, Gabaldon DM, Walker MK, Smith SM. Aryl hydrocarbon receptor null mice develop cardiac hypertrophy and increased hypoxia-inducible factor1alpha in the absence of cardiac hypoxia. Cardiovasc Toxicol 2002;2:263-74.

5. Fernandez-Salguero PM. Immune system impairment and hepatic fibrosis in mice lacking the dioxin-binding Ah receptor. Science 1995;268:722-6.

6. Kimura A, Naka T, Nohara K, Fujii-Kuriyama Y, Kishimoto T. Aryl hydrocarbon receptor regulates Stat1 activation and participates in the development of Th17 cells. Proc Natl Acad Sci U S A 2008;105:9721-6.

7. Chen HS, Perdew GH. Subunit composition of the heteromeric cytosolic aryl hydrocarbon receptor complex. J Biol Chem 1994;269:27554-8.

8. Nguyen TA, Hoivik D, Lee JE, Safe S. Interactions of nuclear receptor coactivator/corepressor proteins with the aryl hydrocarbon receptor complex. Arch Biochem Biophys 1999;367:250-7.

9. Denison MS, Fisher JM, Whitlock JP, Jr. The DNA recognition site for the dioxin-Ah receptor complex. Nucleotide sequence and functional analysis. J Biol Chem 1988;263:17221-4.

10. Qiang M., Dong L, Whitlock Jr. JP. Transcriptional activation by the mouse $\mathrm{Ah}$ receptor. J Biol Chem 1995;270:12697-703.

11. Shimada T, Fujii-Kuriyama Y. Metabolic activation of polycyclic aromatic hydrocarbons to carcinogens by cytochromes P450 1A1 and 1B1. Cancer Sci 2004;95:1-6.

12. Fernandez-Salguero PM, Hilbert DM, Rudikoff S, Ward JM, Gonzalez FJ. Aryl-hydrocarbon receptordeficient mice are resistant to 2,3,7,8 tetrachlorodibenzop-dioxin-Induced toxicity. Toxicol Appl Pharmacol 1996;140:173-9.

13. Safe S. Molecular biology of the Ah receptor and its role in carcinogenesis. Toxicol Lett 2001;120:1-7. 
14. Dragan YP, Chrenk D. Animal studies addressing the carcinogenicity of TCDD (or related compounds) with an emphasis on tumour promotion. Food Addit Contam 2000;17:289-302.

15. Poland A, Teitelbaum P, Glover E. [125I]2-iodo-3,7,8trichlorodibenzo-p-dioxin-binding species in mouse liver induced by agonists for the Ah receptor: characterization and identification. Mol Pharmacol 1989;36:113-20.

16. Kransler KM, McGarrigle BP, Olson JR. Comparative developmental toxicity of 2,3,7,8-tetrachlorodibenzo-pdioxin in the hamster, rat and guinea pig. Toxicology 2007;229:214-25.

17. Denison MS, Vella LM, Okey AB. Structure and function of the Ah receptor for 2,3,7,8-tetrachlorodibenzop-dioxin. Species difference in molecular properties of the receptors from mouse and rat hepatic cytosols. J Biol Chem 1986;261:3987-95.

18. Caramaschi F, del Corno G, Favaretti C, Giambelluca SE, Montesarchio E, Fara GM. Chloracne following environmental contamination by TCDD in Seveso, Italy. Int J Epidemiol 1981;10:135-43.

19. Moriguchi T, Motohashi H, Hosoya T, Nakajima O, Takahashi S, Ohsako S, et al. Distinct response to dioxin in an arylhydrocarbon receptor (AHR)-humanized mouse. Proc Natl Acad Sci USA 2003;100:5652-7.

20. Connor KT, Aylward LL. Human response to dioxin: aryl hydrocarbon receptor (AhR) molecular structure, function, and dose-response data for enzyme induction indicate an impaired human AhR. J Toxicol Environ Health B Crit Rev 2006;9:147-71.

21. Flaveny C, Reen RK, Kusnadi A, Perdew GH. The mouse and human $\mathrm{Ah}$ receptor differ in recognition of LXXLL motifs. Arch Biochem Biophys 2008;471:215-23.

22. Korkalainen M, Tuomisto J, Pohjanvirta R. The AH receptor of the most dioxin-sensitive species, guinea pig, is highly homologous to the human $\mathrm{AH}$ receptor. Biochem Biophys Res Commun 2001;285:1121-9.

23. Keiko N, Kana A, Yoshimi M, Tomohiro I, Takehiro S, Hiroyoshi $\mathrm{T}$, et al. Comparison of the 2,3,7,8tetrachlorodibenzo-p-dioxin (TCDD)-induced CYP1A1 gene expression profile in lymphocytes from mice, rats, and humans: most potent induction in humans. Toxicology 2006:49465-75.

24. Flaveny CA, Murray IA, Chiaro CR, Perdew GH. Ligand selectivity and gene regulation by the human aryl hydrocarbon receptor in transgenic mice. Mol Pharmacol 2009;75:1412-20.

25. Ramadoss P, Perdew GH. Use of 2-Azido-3-[125I]iodo7,8-dibromodibenzo-p-dioxin as a probe to determine the relative ligand affinity of human versus mouse aryl hydrocarbon receptor in cultured cells. Mol Pharmacol 2004;66:129-36.

26. Ema M, Ohe N, Suzuki M, Mimura J, Sogawa K, Ikawa S, et al. Dioxin binding activities of polymorphic forms of mouse and human arylhydrocarbon receptors. J Biol Chem 1994;269:27337-43. 